Open Access

\title{
Molecular characterization and classification of Trypanosoma spp. Venezuelan isolates based on microsatellite markers and kinetoplast maxicircle genes
}

E. Sánchez ${ }^{1}$, T. Perrone ${ }^{1 \wedge}$, G. Recchimuzzi ${ }^{2}$, I. Cardozo ${ }^{1}$, N. Biteau ${ }^{3}$, PM Aso ${ }^{2}$, A. Mijares ${ }^{1}$, T. Baltz ${ }^{3}$, D. Berthier ${ }^{4}$, L. Balzano-Nogueira ${ }^{5}$ and Ml Gonzatti $i^{*}$

\begin{abstract}
Background: Livestock trypanosomoses, caused by three species of the Trypanozoon subgenus, Trypanosoma brucei brucei, T. evansi and T. equiperdum is widely distributed throughout the world and constitutes an important limitation for the production of animal protein. T. evansi and T. equiperdum are morphologically indistinguishable parasites that evolved from a common ancestor but acquired important biological differences, including host range, mode of transmission, distribution, clinical symptoms and pathogenicity. At a molecular level, T. evansi is characterized by the complete loss of the maxicircles of the kinetoplastic DNA, while T. equiperdum has retained maxicircle fragments similar to those present in T. brucei. T. evansi causes the disease known as Surra, Derrengadera or "mal de cadeiras", while T. equiperdum is the etiological agent of dourine or "mal du coit", characterized by venereal transmission and white patches in the genitalia.

Methods: Nine Venezuelan Trypanosoma spp. isolates, from horse, donkey or capybara were genotyped and classified using microsatellite analyses and maxicircle genes. The variables from the microsatellite data and the Procyclin PE repeats matrices were combined using the Hill-Smith method and compared to a group of T. evansi, $T$. equiperdum and T. brucei reference strains from South America, Asia and Africa using Coinertia analysis. Four maxicircle genes (cytb, cox1, a6 and nd8) were amplified by PCRfrom TeAp-N/D1 and TeGu-N/D1, the two Venezuelan isolates that grouped with the T. equiperdum STIB841/OVI strain. These maxicircle sequences were analyzed by nucleotide BLAST and aligned toorthologous genes from the Trypanozoon subgenus by MUSCLE tools. Phylogenetic trees were constructed using Maximum Parsimony (MP) and Maximum Likelihood (ML) with the MEGA5.1 $1^{\oplus}$ software.

(Continued on next page)
\end{abstract}

\footnotetext{
* Correspondence: mgonzat@usb.ve

Deceased

${ }^{2}$ Grupo de Bioquímica e Inmunología de Hemoparásitos. Departamento de Biología Celular, Universidad Simón Bolívar, Caracas 1080, Venezuela Full list of author information is available at the end of the article
} 
(Continued from previous page)

Results: We characterized microsatellite markers and Procyclin PE repeats of nine Venezuelan Trypanosoma spp. isolates with various degrees of virulence in a mouse model, and compared them to a panel of T. evansi and T. equiperdum reference strains. Coinertia analysis of the combined repeats and previously reported T. brucei brucei microsatellite genotypes revealed three distinct groups. Seven of the Venezuelan isolates grouped with globally distributed T. evansi strains, while TeAp-N/D1 and TeGu-N/D1 strains clustered in a separate group with the T. equiperdum STIB841/OVI strain isolated in South Africa. A third group included T. brucei brucei, two strains previously classified as T. evansi (GX and TC) and one as T. equiperdum (BoTat-1.1). Four maxicircle genes, Cytochrome b, Cythocrome Oxidase subunit 1, ATP synthase subunit 6 and NADH dehydrogenase subunit 8, were identified in the two Venezuelan strains clustering with the T. equiperdum STIB841/OVI strain. Phylogenetic analysis of the cox1 gene sequences further separated these two Venezuelan T. equiperdum strains: TeAp-N/D1 grouped with T. equiperdum strain STIB818 and T. brucei brucei, and TeGu-N/D1 with the T. equiperdum STIB841/OVI strain.

Conclusion: Based on the Coinertia analysis and maxicircle gene sequence phylogeny, TeAp-N/D1 and TeGu-N/D1 constitute the first confirmed T. equiperdum strains described from Latin America.

Keywords: Trypanosoma equiperdum, Trypanosoma evansi, Maxicircle, Microsatellite genotyping, Coinertia analysis

\section{Background}

Trypanosomes are unicellular parasites that cause important diseases in humans and animals. They comprise a wide group of parasites of vertebrates usually transmitted by haematophagous arthropods [1]. Livestock trypanosomoses caused by Trypanosoma brucei brucei, Trypanosoma equiperdum and Trypanosoma evansi, all belonging to the Trypanozoon subgenus, has a significant socio-economic impact and limits animal protein productivity throughout the world [2-4]. T. evansi, the first pathogenic trypanosome discovered, was found in the blood of horses and camels suffering an endemic disease known as Surra, derrengadera, murrina or "mal de cadeiras" [5]. T. evansi was introduced to America in the XV century through the importation of horses from Africa by Spanish conquerors [5-7]. T. evansi is mechanically transmitted and it is now widely distributed throughout tropical and subtropical regions of Northern Africa, Southeast Asia, as well as Central and South America, where livestock and native wildlife are severely affected $[2,5,8-10]$. In Europe, the importation of dromedary camels from the Canary Islands was associated with $T$. evansi outbreaks in France and Spain $[11,12]$ and chronic T. evansi infection and death was reported in a dog that returned to Germany after international travel [13].

T. evansi is morphologically indistinguishable from the two other pathogenic species, T. brucei and T. equiperdum [5, 14-17]. T. equiperdum is the causative agent of dourine, a distinctive disease that only affects Equidae and is transmitted mainly via coitus [16, 18-22]. Because T. evansi, T. equiperdum and T. brucei species cannot be distinguished by sequences of their ribosomal RNA (rRNA) genes [1, 23-27], other probes, including isoenzymes and peptidase profiles [28-30], restriction fragment length polymorphisms [31], kinetoplast sequences [32, 33] and microsatellites markers [34] have been used to characterize and distinguish these trypanosome species. Simple sequence repeat (SSR) microsatellites are DNA loci with tandemly repeated short sequence motifs, whose copy number is hypervariable at each locus [35, 36]. The mutation rate of SSR microsatellites, and thus their variability, is higher than that observed for isoenzyme or RFLP markers [37-39], making them highly useful for studying the relationships between closely related species or within populations of the same species [40, 41].

All Kinetoplastids, including the species within the Trypanozoon subgenus, contain kinetoplasts, a concatenated network of complex mitochondrial DNA comprising 5.000-10.000 minicircles of about 1000 bp [42], T. brucei minicircles sequences are highly heterogeneous [43] while the minicircles from T. evansi strains from Africa, Asia and South America, show extensive sequence conservation [44-47]. With the exception of Trypanosoma evansi, all species within the Trypanosoma genus contain 50-100 complete or partial maxicircles varying in size from $20 \mathrm{Kbp}$ for T. brucei ssp. to $40 \mathrm{kbp}$ for C. fasciculata [48]. The maxicircles encode mitochondrial genes necessary for development and differentiation in the insect vector [48-51].

We previously showed that Venezuelan Trypanosoma spp. isolates separated into two groups, according to their RAPD profiles [52]. Seven of the nine Venezuelan isolates clustered together, while two highly virulent horse isolates, TeAp-N/D1 and TeGu-N/D1, appeared to be genetically distinct $[17,52,53]$. By analyzing microsatellite loci and PE repeats, we found that the seven less virulent isolates clustered with $T$. evansi reference strains, while the more virulent TeAp-N/D1 and TeGu-N/D1 isolates closely matched a T. equiperdum reference strain, leading us to look for the presence of maxicircle genes. 


\section{Methods}

\section{Trypanosoma spp. field isolates and DNA extraction}

Nine Venezuelan Trypanosoma spp. isolates were obtained from horse, donkey or capybara blood samples, as previously described [52]: TeAp-Cedral05, TeAp-Cedral12, TeAp-ElFrío01, TeAp-Mantecal01, TeAp-N/D1, TeGu-N/ D1, TeGu-Terecay01, TeGu-Terecay03 and TeGuTerecay323. The trypanosomes were expanded in rats and purified by ion exchange chromatography (DEAE-Cellulose) [54]. Parasites were quantified with a hemocitometer and genomic DNA was extracted using a commercial kit (BDtract $^{\mathrm{TM}}$, Maxim Biotech, Inc). DNA concentration and purity were determined in a SmartSpect ${ }^{\mathrm{TM}} 3000$ (BioRad). The DNA and PCR amplification products were analyzed by agarose gel electrophoresis under standard conditions.

\section{Ethical approval}

The project was approved by the COBIANIM (IVICDIR-1073/12) an advisory body of IVIC with regard to the ethical use of animals in research, in accordance with national and international standards. This committee oversees all research activities at IVIC, requiring the use of animals and wildlife to meet with Venezuelan law and universal ethical values. The Commission assessed the methodological, bioethical and legal aspects of this project by resolution IVIC/ $\mathrm{N}^{\mathrm{O}} 1444$ [55].

\section{Microsatellite and Procyclin PE-typing}

The PCR amplifications for microsatellite analysis were performed with an Eppendorf Mastercycler, as described [34]. Five microsatellite markers were employed, four that were previously used to characterize trypanosome isolates [34], and a fifth new genetic marker MD2.349-CA amplified with primers MD2.349-CA-F (GCATGCGTGAG GAAGTGAG) and MD2.349-CA-R (GTCCTGTTGGC CGCATTAT) and also a sequence corresponding to the Procyclin PE repeats. The lengths of the PCR products were determined using the Genescan software (Applied Biosystems), and they were sequenced using an ABI 3130 XL (Applied Biosystems) at the C.G.F.B. (Functional Genomic Center of Bordeaux, France).

\section{Multivariate analysis}

Two matrices were generated based on genotyping with microsatellite and Procyclin PE repeats (Additional file 1) and previously published data on T. brucei brucei [34]. The categorical values matrix contains all the evaluated microsatellite data, classified from the lowest to the highest number of repeats. The binary values matrix was constructed with the Procyclin PE repeats data, where (0) was the absence and (1) the presence of a determined PE repeat. When each qualitative variable is represented by binary indicator variables for each category, specifying whether an object belongs to it (1) or not (0), multiple correspondence analysis (MCA) can be formulated as a principal component analysis (PCA) of the total set of these indicator variables with respect to some predefined metrics. Thus, just as in PCA, object coordinates can be seen as component scores determined up to a rotation only [56].

By applying this transformation it was possible to use the Hill-Smith [57] method to combine categorical and binary variables to compare all Trypanosoma spp. isolates and strains in a Coinertia analysis $[58,59]$. This method is a combination of a multiple correspondence analysis (MCA) for categorical data matrix and MCA rotated to principal component analysis (PCA) for binary data matrix. It was implemented with functions of the ADE-4 package from the $\mathrm{R}$ software ${ }^{\bullet}$ [60-62].

\section{PCR amplification of maxicircle genes}

Four maxicircle sequences were amplified using either previously reported primers or novel primers designed for this study, based on the complete sequences of the following $T$. brucei genes: Cytochrome b (cytb-GenBank Accession $\mathrm{N}^{\circ}$ M17998); Cytochrome oxidase Subunit 1 (cox1 -GenBank Accession $\mathrm{N}^{\circ}$ M14820); ATP synthase subunit 6 (a6-GenBank Accession $\mathrm{N}^{\circ} \mathrm{M} 14820$ ); and NADH Dehydrogenase Subunit 8 (nd8 -GenBank Accession $N^{\circ}$ M63820.1). Primer sequences and PCR conditions are shown in Additional file 2: Table S1. The cytb and cox 1 gene amplifications were performed with DNA from all nine Venezuelan isolates, while the $a 6$ and $n d 8$ amplifications were carried out only with DNA from TeAp-N/D1 and TeGu-N/D1.

The $c y t b, c o x 1, a 6$ and $n d 8$ amplicons were purified prior to sequencing using the AccuPrep ${ }^{\oplus}$ PCR Purification Kit $\left(B I O N E E R^{\odot}\right)$ according to the manufacturer's instructions. Sequencing of the TeAp-N/D1 genes: $c y t b$ [GenBank: KP729379), cox1 [GenBank: KP729381], a6 [GenBank: KP729385] and nd8 [GenBank: KP729383] and the corresponding TeGu-N/D1 genes: cytb [GenBank: KP729380], cox1 [GenBank: KP729386], a6 [GenBank: KP729382] and nd8 [GenBank: KP729384] was performed by Macrogen (Korea) and Unidad de Estudios Genéticos y Forenses (UEGF-Instituto Venezolano de Investigaciones Científicas, Venezuela).

\section{Sequence analysis and alignment}

Maxicircle sequences from TeAp-N/D1 and TeGu-N/D1 isolates were compared to the corresponding sequences from T. equiperdum, T. brucei sp. and T. brucei brucei retrieved from the Genbank database. Sequence analysis was performed using nucleotide BLAST and the sequences were aligned by MUSCLE tools. Phylogenetic trees were constructed using Maximum Parsimony (MP) and Maximum Likelihood (ML) with the MEGA5.1 ${ }^{\circledR}$ software [63] using T. cruzi as an outgroup. For the ML method, the evolution of the aligned sequences was analyzed. 


\section{Results}

We analyzed nine Trypanosoma spp. isolates obtained from two Venezuelan states (Apure and Guárico) and from three different hosts: horses, donkeys and capybara. We previously showed that the RAPDs profile of the TeAp-N/D1 and TeGu-N/D1 isolates (horse) were quite distinct from the other seven Venezuelan isolates [52]. To further characterize these strains, all nine Trypanosoma spp. isolates were genotyped using microsatellites and Procyclin repeats followed by multivariate analysis, and the two that clustered with T. equiperdum (STIB841/ OVI), TeAp-N/D1 and TeGu-N/D1, were analyzed for specific maxicircle gene sequences.

\section{Genotyping}

The results of the microsatellite and Procyclin PE repeats analysis of the nine Trypanosoma spp. Venezuelan isolates, along with the corresponding data from fifteen T. evansi, three T. equiperdum and eighteen T. b. brucei reference strains are presented in Additional file 1. The Trypanozoon reference strains used in this study originated from Latin America (Colombia and Brazil), Asia (China) and Africa (Chad, Kenya, Ethiopia, Gambia, Ivory Coast, Burkina Faso, Nigeria, Democratic Republic of Congo, Uganda, Tanzania and South Africa).

Five SSR microsatellites and the PE repeats of the PARP genes were used to analyze the nine Venezuelan isolates. The resulting genotypes were compared to reference T. evansi and T. equiperdum strains, as well as to eighteen previously reported $T$. brucei brucei strains [34], by coinertia analysis.

\section{Coinertia analysis}

The rotated binary-matrix was constrained with the categorical data matrix by the Hill-Smith method to be able to perform a coinertia analysis that explained $53.68 \%$ and $22.161 \%$ of the observed inertia in the microsatellites hyperspace ( $\mathrm{X}$ matrix in $\mathrm{x}$ axis) and the Procyclin PE repeats hyperspace ( $\mathrm{Y}$ matrix in y axis), respectively (Fig. 1a and 1b). The two markers, MORF2-CA and MEST19-AT/ GT, contributed most to the construction of the coinertia first axis with $80.31 \%$ and $62.58 \%$ on average per allele, respectively. In the second coinertia axis, Repeats 24 and 28 contributed most with $72.67 \%$ and $66.81 \%$, respectively. Figure 1c revealed three distinct groups, one with $T$. evansi strains, a second group with all the T. brucei brucei strains and a third group with the $T$. equiperdum STIB841/OVI strain and the two Venezuelan isolates from this study, TeAp-N/D1 and TeGu-N/D1, shown with black arrows. The remaining seven Venezuelan Trypanosoma spp. isolates are close to the $T$. evansi reference strains from the first group. The coinertia analysis of the available genotyping data showed that four of the T. evansi strains, namely JX, TC, ET and 80 are genetically distinct. Interestingly, one of them, the TC strain, is closely related to the T. b. brucei group (Fig. 1c). The B1 and BJ T. equiperdum references strains are different from the STIB841/ OVI strain (Fig. 1c). Based on the PE repeats, the T. evansi KETRI2480 and T. equiperdum BJ strains are closely related (Fig. 1c). The wide distribution of T. evansi and T. equiperdum strains among distinct groups strongly supports multiple evolutionary origins for these dyskinetoplastic strains.

\section{Amplification of maxicircle genes}

Because the presence of maxicircles is a universally accepted marker to distinguish T. equiperdum from $T$. evansi, amplification of two maxicircle genes (cytb and cox1), was attempted in the nine Venezuelan Trypanosoma spp. isolates. In agreement with the microsatellite data, no amplification of cytb and cox 1 was observed in the seven Venezuelan Trypanosoma spp. isolates that belong to the main $T$. evansi cluster: TeAp-Cedral05, TeAp-Cedral12, TeGu-Terecay03, TeAp-El Frío01, TeApMantecal01, TeGu-Terecay323 and TeGu-Terecay01. However both cytb and coxl could be amplified from DNA of the TeAp-N/D1 and TeGu-N/D1 isolates, as were, two additional maxicircle genes, ATP synthase subunit 6 (a6) and NADH dehydrogenase subunit 8 (nd8).

\section{Phylogenetic analysis of four maxicircle genes}

Analysis of the sequences of the cytb, cox $1, a 6$ and $n d 8$ genes amplified from the TeAp-N/D1 and TeGu-N/D1 isolates with BLASTn revealed maximum identities between 98 and $99 \%$ to the orthologous genes from $T$. equiperdum strain STIB842 and BoTat1.1 (Additional file 2: Tables S2-S9). In addition, cox1 from TeAp-N/D1 was $99 \%$ identical to the corresponding gene from $T$. brucei strain [GenBank: M14820] (Additional file 2: Table S4).

Phylogenetic trees were constructed using both maximum parsimony and maximum likelihood, with T. cruzi as outgroup. The $c y t b$ analysis showed that TeAp-N/D1 and TeGu-N/D1 are closely related to the T. equiperdum STIB841/OVI strain (Fig. 2a). The phylogenetic relationship of $\operatorname{cox} 1$ sequences shows three different subgroups, one including TeAp-N/D1 and the T. equiperdum STIB818 and three T. brucei strains, a second group comprising TeGu-N/D1 and the T. equiperdum STIB841/ OVI strain and a third group with the T. equiperdum STIB842 and BoTat1.1 strains (Fig. 2b). The phylogenetic construction estimated with the $a 6$ sequences shows the TeGu-N/D1 strain as a separate group, while TeAp-N/D1 showed identity with three T. brucei strains and two $T$. equiperdum STIB842/ BoTat1.1 strains (Fig. 3a). The $n d 8$ sequences of TeAp-N/D1 and TeGu-N/D1 were identical and related to T. equiperdum STIB842 and BoTat1.1 strains (Fig. 3b). 
A Procyclin PE repeats ( $\mathrm{Y}$ ) hyperspace

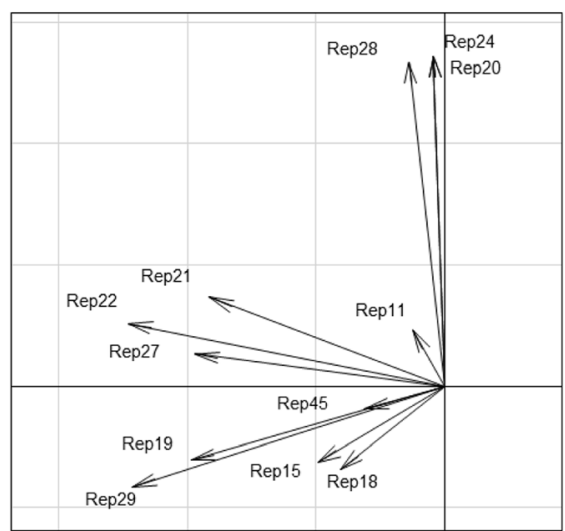

B Microsatellites $(X)$ hyperspace

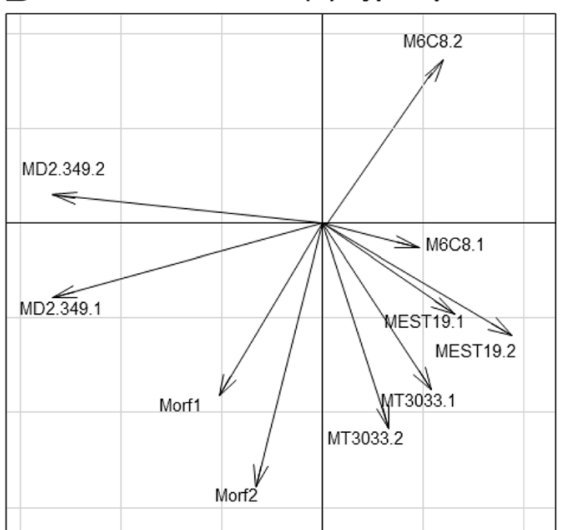

C

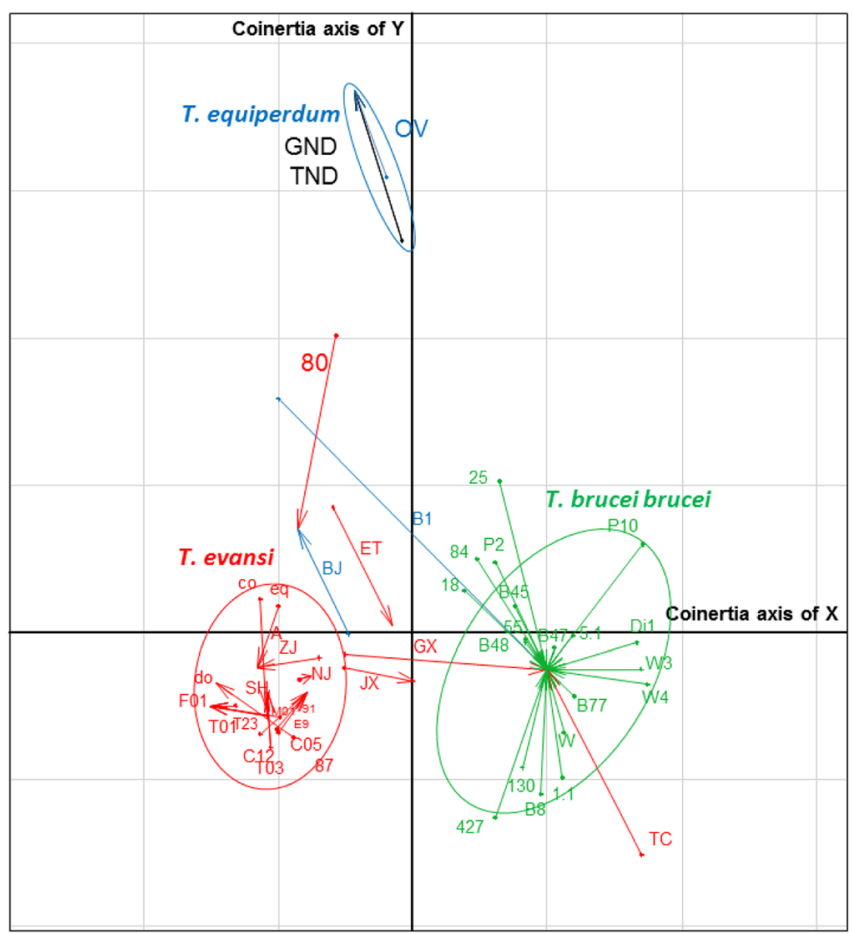

Fig. 1 Coinertia analysis by the Hill-Smith method combining microsatellites and Procyclin PE repeats. (a) and (b) scatterplots represent the coefficients of the combinations of the variables for each data matrix to define the coinertia axes. Separate analyses find axes maximizing inertia in each hyperspace. These axes are projected in the scatterplot (c) on which the Trypanosoma spp. isolates and reference strains are also projected. The beginning of the arrows is the position of the isolate described by the microsatellite data matrix and the end of the arrow is the position of the isolate described by the procyclin PE repeats. Arrows of the same species were grouped in ellipses of $95 \%$ of variance observed, identifying three groups: $T$. evansi (red), T. brucei brucei (green) and T. equiperdum (blue). T. evansi and T. equiperdum isolates that fell outside the major groups were not used to calculate the confidence ellipses. The analysis explained $53.68 \%$ in the microsatellites hyperspace and $22.16 \%$ in the Procyclin PE repeats hyperspace of the observed inertia with a Rv Escoufier similarity coefficient of 0.424415. C05: TeAp-Cedral05; C12:TeAp-Cedral12; T03: TeGu-Terecay03; F01:

TeAp-EIFrio01; M01: TeAp-Mantecal01; T23: TeGu-Terecay323; T01: TeGu-Terecay01; TND: TeAp-N/D1; GND: TeGu-N/D1; E9: E9/CO; 87: 2187; 91: 2191; A: A; do: dog; eq: equi; co: coati; SH: SH; ZJ: ZJ; NJ: NJ; GX: GX; JX: JX; TC: TC; ET: ET; 80: KETRI 2480; OV: STIB841/OVI; B1: BoTat-1.1; BJ: BJ; 5.1: AnTat-5/1; 55: LM 55; 18: LM 118; 84: LM 184; 25: LM 225; P10: KP10; 130: PTAG 130 (IPR-01130); P2: KP2; Di1: DiTat-1; B8: B8/18; W3: SW3/87; W4: SW4/87; W: SW 161/87; B45: STIB 345; B77: STIB-777.AE; 1.1: AnTat-1/1; 427: EATRO-427; B47: STIB247.LFB; B48: STIB348

The pattern and multivariate analysis of microsatellite and PE repeats from seven of the Trypanosoma spp. isolates, TeAp-Cedral05, TeAp-Cedral12, TeAp-ElFrío01, TeAp-Mantecal01, TeGu-Terecay323, TeGu-Terecay01,
TeGu-Terecay03, as well as the lack of amplification of two of the maxicircle genes confirmed that these seven isolates belong to the T. evansi group, while the genotype and coinertia analysis of TeAp-N/D1 and TeGu-N/ 


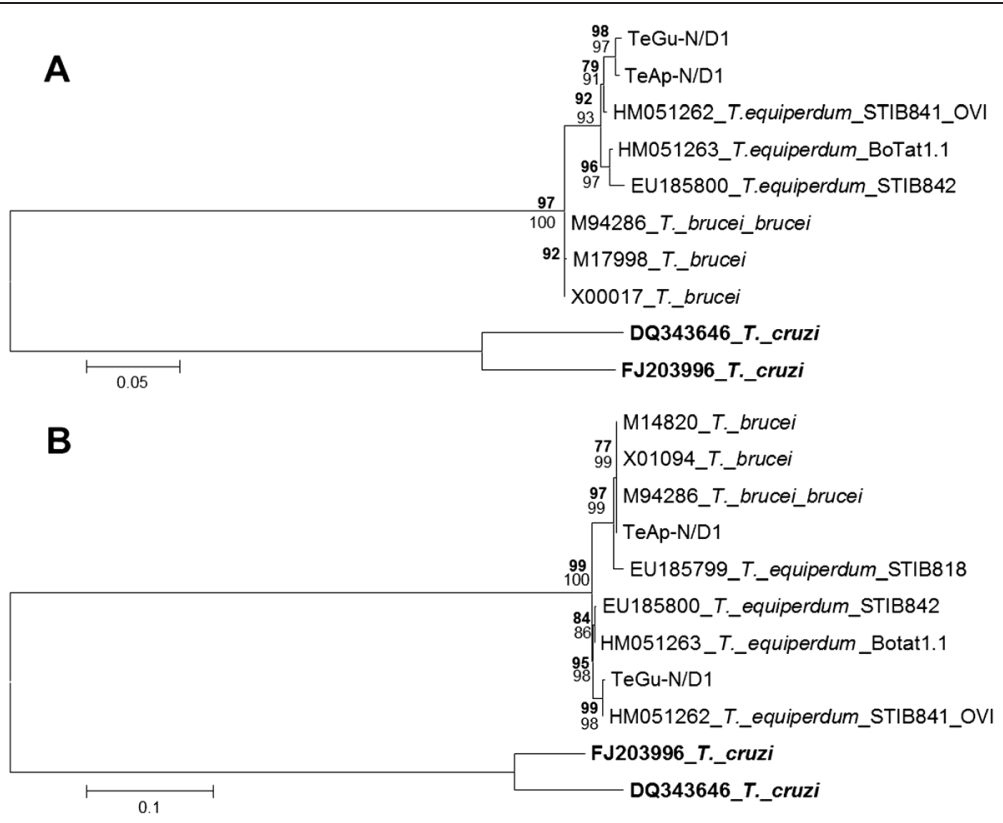

Fig. 2 Phylogenetic Relationship of cytb and cox 1 gene sequences for two Venezuelan Trypanosoma spp. isolates. Phylogenetic trees for the cytb (a) and $\operatorname{cox} \mathbf{1}$ (b) gene sequences were inferred by Maximum Parsimony (MP, bold numbers) and Maximum Likelihood (ML) methods in MEGA 5.1 ๑ 500 replicates (bootstrap $>75 \%$ are shown). T. cruzi was used as outgroup. The tree topology shown corresponds to the ML method derived from previous evolutionary sequence alignment. $c y t b=$ Hasegawa-Kishino-Yano $(H K Y)+$ Gamma distribution. $\operatorname{cox} \mathbf{1}=H K Y+\operatorname{Invariant}$ sites

D1 showed that they are closely related to the T. equiperdum STIB841/ OVI strain (Table 1). Further, comparison of the sequences of maxicircle gene $\operatorname{cox} 1$ separated the TeAp-N/D1 and TeGu-N/D1 isolates, so that TeAp-N/D1 isolate clustered with T. equiperdum STIB818 and T. brucei brucei, while the TeGu-N/D1 grouped with the T. equiperdum STIB841/OVI.

\section{Discussion}

The classification of trypanosomes within the Trypanozoon sub-genera was originally based on morphological and morphometrical criteria, as well as clinical manifestations, host range and geographical distribution. In the last several years, molecular markers such as microsatellite loci and sequence analysis of the rRNA and gGAPDH

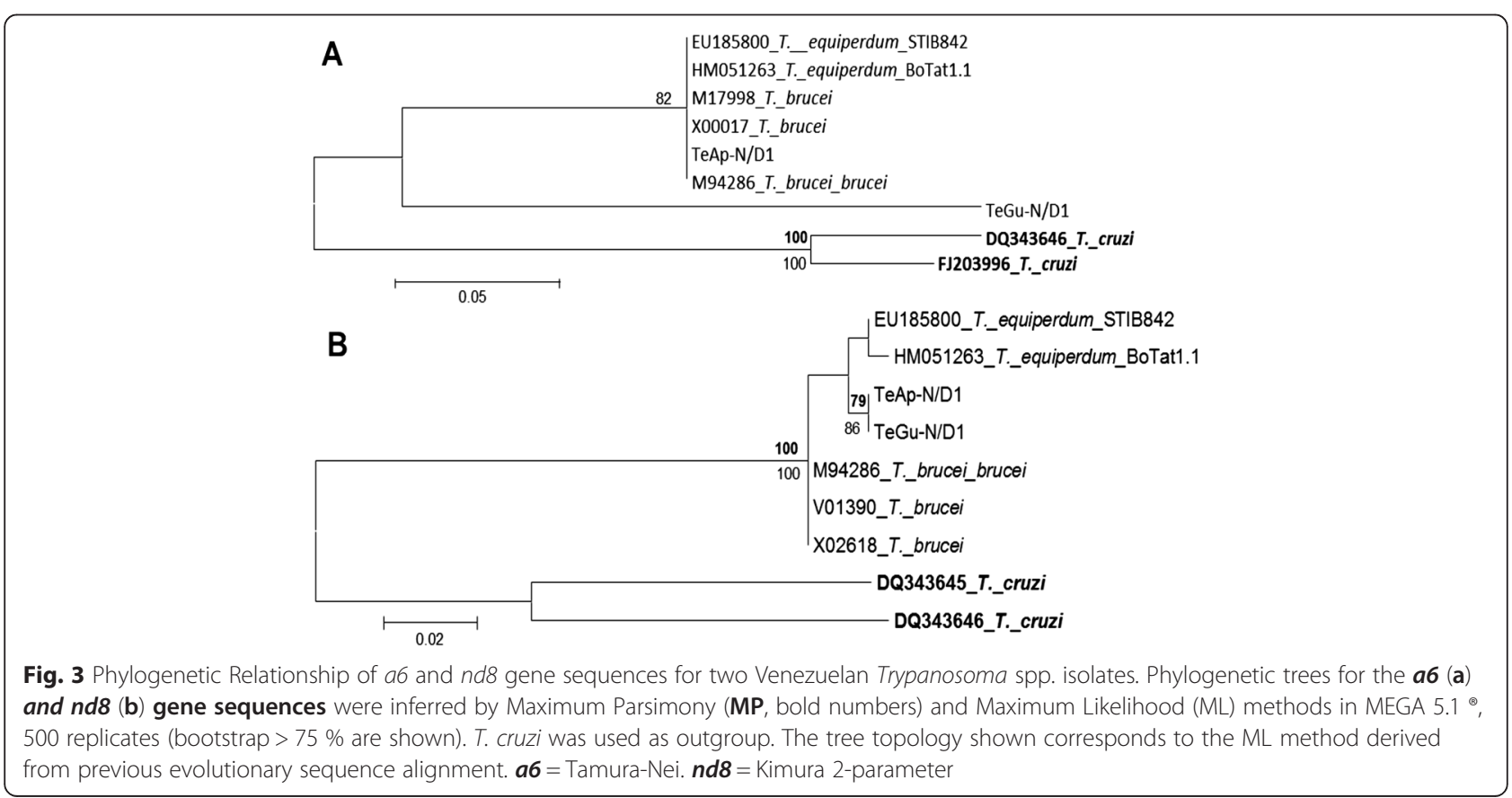


Table 1 Summary of the Venezuelan T. evansi and T. equiperdum strains characterized in this study

\begin{tabular}{|c|c|c|}
\hline Strain (host) & $\begin{array}{l}\text { Microsatellite Genotyping } \\
\text { and Coinertia analysis }\end{array}$ & Maxicircle genes \\
\hline \multicolumn{3}{|l|}{ T. evansi } \\
\hline TeAp-Cedral05 (capybara) & \multirow{8}{*}{$\begin{array}{l}\text { Closely related to } \\
\text { T. evansi references } \\
\text { strains from South } \\
\text { America (Brazil } \\
\text { and Colombia) } \\
\text { and Asia (China). }\end{array}$} & n.a. \\
\hline TeAp-Cedral12 (capybara) & & n.a. \\
\hline TeAp-ElFrío01 (capybara) & & n.a. \\
\hline TeAp-Mantecal01 (horse) & & n.a. \\
\hline TeGu-Terecay03 (donkey) & & n.a. \\
\hline TeGu-Terecay01 (donkey) & & n.a. \\
\hline TeGu-Terecay323 (donkey) & & n.a. \\
\hline \multicolumn{2}{|l|}{ T. equiperdum } & \\
\hline TeAp-N/D1 (horse) & $\begin{array}{l}\text { Closely related to the } \\
\text { T. equiperdum } \\
\text { STIB841/ OVI strain }\end{array}$ & $\begin{array}{l}\text { Positive for } \\
c y+b \text {, coxl, } \\
a 6 \text { and nd8 }\end{array}$ \\
\hline TeGu-N/D1 (horse) & $\begin{array}{l}\text { Closely related to the } \\
\text { T. equiperdum } \\
\text { STIB841/OVI strain. }\end{array}$ & $\begin{array}{l}\text { Positive for } \\
c y+b, \text { coxl, } \\
a 6 \text { and nd8 }\end{array}$ \\
\hline
\end{tabular}

na: not amplified by PCR. The nomenclature, natural hosts and molecular characteristics of the nine Venezuelan strains included in this study are presented. The geographical origin of the strains has been previously reported [52]

genes have been used to describe the evolutionary relationships among organisms. This has led to the re-evaluation of what constitutes a trypanosome species $[5,34$, 64, 65]. The lack of maxicircle genes in T. evansi has been used to differentiate it from T. equiperdum [33], both being considered as petite mutants of $T$. brucei [51]. Subtle genomic changes were found between the akinetoplastic strain T. evansi STIB805 and the T. $b$. brucei TREU 927/4 strain, supporting the view that $T$. evansi should be considered a subspecies of T. brucei [66]. The species or subspecies status of both $T$. evansi and T. equiperdum has been debated by several authors and continues to be polemical $[4,16,51,66,67]$.

Using RAPD analysis, we previously showed that nine Venezuelan Trypanosoma spp. isolates cluster into two separate groups, one with seven isolates that share a similar genetic pattern and a second, distinct group of two horse isolates, TeAp-N/D1 and TeGu-N/D1 that appeared identical except with one of the forty random primers [52]. Since these nine Venezuelan Trypanosoma spp. isolates were presumed to belong to the Trypanozoon group, we used microsatellites markers and PARP-PE repeats to compare them to T. evansi and T. equiperdum reference strains. These loci exhibited limited polymorphism among seven of our isolates and the T. evansi reference strains from various hosts, horse, dog, coati, bovine, buffalo, mule and camels and geographical origins, South America, Asia and Africa. However, the microsatellite analysis clearly clustered two of the Venezuelan Trypanosoma spp. horse isolates with the T. equiperdum STIB841/OVI strain from South Africa.

Coinertia analysis of the microsatellite and PE repeats revealed that seven of the nine Venezuelan isolates closely match eleven $T$. evansi reference strains from around the world, while TeAp-N/D1 and TeGu-N/D1 are identical to the South African $T$. equiperdum STIB841/OVI strain. Principal Component Analysis (PCA) of microsatellite markers showed that this $T$. equiperdum strain is closely related to the T. brucei brucei Kiboko group [66]. In agreement with previous studies of Trypanozoon microsatellite loci [34], our coinertia analysis showed that BoTat-1.1 and BJ were highly heterogeneous $T$. equiperdum strains, genetically distant from the group that included the two Venezuelan $T$. equiperdum strains and STIB841/OVI. Four independent T. evansi/T. equiperdum genotypes have been recently described by Carnes et al [66]. They classified two of the reference T. equiperdum strains included in this study, BoTat-1.1 (Teq21) and STIB841/OVI, within groups 2 and 3 , respectively.

Since T. equiperdum is distinguished from T. evansi by the presence of partially deleted maxicircles [14, 51, 67], we amplified and sequenced maxicircle genes from the TeAp-N/D1 and TeGu-N/D1 isolates and analyzed the resulting phylogenetic relationships. In agreement with previous reports, the two Venezuelan T. equiperdum strains analyzed in this study, TeAp-N/D1 and TeGu-N/ D1, have retained at least four maxicircle genes [51]. ND8 and A6 constitute complexes I and V of the oxidative phosphorylation system, and their expression is essential in the T. brucei bloodstream form $[68,69]$, as is the expression of $c y t b$ [70]. A6 is important for maintaining the mitochondrial membrane potential and several mutations that affect its function have been described in diskinetoplastic trypanosomes [71-73]. Mitochondrial genes have been proposed as excellent molecular markers for discriminating closely related species [74-76]. The four maxicircle genes from the TeAp-N/D1 and TeGu-N/ D1 isolates revealed a close relationship to both $T$. brucei and T. equiperdum strains. The phylogenetic analysis of $\operatorname{cox} 1$ gene sequences is concordant with the four distinct groups of T. evansi and T. equiperdum strains that suggest four independent origins of these diskinetoplastic parasites [66]. Interestingly, while the microsatellite loci and Procyclin PE repeats and coinertia analyses showed identical genotypes for TeAp-N/D1 and TeGu-N/D1, the cox1 and $a 6$ mitochondrial markers separated them into different clusters. These results confirm the first molecular report of T. equiperdum strains (TeAp-N/D1 and TeGu-N/ D1) isolated in Venezuela or in any part of Latin America.

Interestingly, T. equiperdum is not a typical American parasite but dourine, a sexually transmitted chronic disease in horses, mules and donkeys [5, 17], has been 


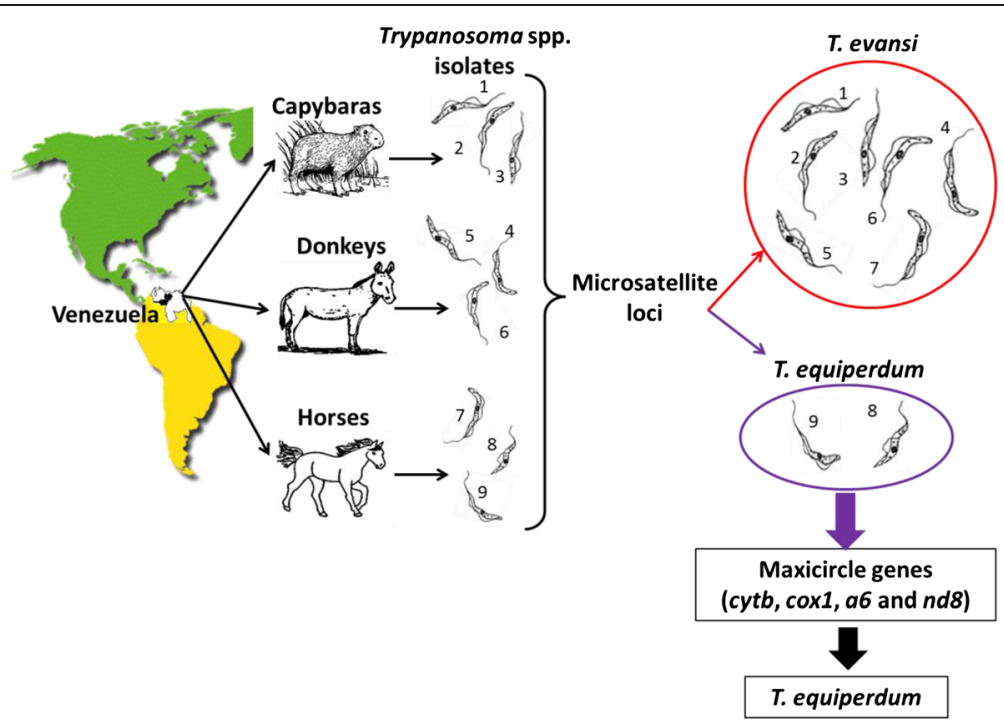

Fig. 4 Microsatellites and four maxicircle genes were used to characterize nine Trypanosoma spp. Venezuelan isolates. Seven isolates were shown to be closely related to T. evansi reference strains, while two were classified as T. equiperdum

sporadically reported in the American continent from Canada (1921) to the USA (1934) and Mexico (1973) [77]. In Venezuela, clinical dourine was first recorded by the presence of dourine plaques in a domestic male horse, but no parasites were observed [78]. The actual geographical distribution of dourine is not known and trade restrictions appear to limit notification of the disease. The disease was widespread in the past but was eradicated from many countries of Europe after the 1940s [22, 79]. Currently, the disease is endemic in parts of Africa, Asia and Russia, and dourine outbreaks or incidents have been occasionally reported in the Middle East and Europe [16, 80-82]. However, dourine may exist in areas where diagnostic tests are not routinely performed [3, 17]. In 2011, seven dourine outbreaks were confirmed in various regions of Italy [18-21, 83], all linked to the movement of breeding animals showing the characteristic plaques and lesions. The presence of T. equiperdum was confirmed by RT-PCR.

T. equiperdum is morphologically indistinguishable from T. evansi and T. brucei, $[5,17]$. T. evansi was initially proposed to have evolved from an ancestral T. bru$c e i$ when infected camels were introduced to Glossina-free areas $[5,14]$ and is characterized by the absence of maxicircle structures [45, 84]. Several years ago, Claes et al [16] proposed that $T$. equiperdum does not exist as a separate species and that extant strains are either T.b. equiperdum, or misidentified T.b. brucei or T. evansi strains. Based on genetic analysis, other authors have also proposed that $T$. evansi and T. equiperdum should be considered subspecies of $T$. brucei $[16,17,51,65,66]$. In contrast, Desquesnes et al [4] recommend keeping the current species status for T. evansi and T. equiperdum, in agreement with the rules of the international code for zoological nomenclature and based on their significant biological differences. Further genomic analysis of the two Venezuelan T. equiperdum strains should shed new light on the evolution, origin and pathogenic effects of these trypanosomes.

The evolution of $T$. evansi and T. equiperdum has been revisited in recent years. Lun et al [67] proposed two sequential steps in the spreading of $T$. brucei out of Africa, the first involved the homogenization of minicircles in the T. b. brucei bloodstream form and the loss of the ability to differentiate within the insect vector, resulting in $T . b$. equiperdum. Over generations, the gradual loss of maxicircles occurred due to the lack of selective pressure to preserve them, giving rise to $T . b$. equiperdum and eventually $T . b$. evansi, which lacks all maxicircles. An alternative model proposed that an ancestral trypanosome lost maxicircle genes in three [85] or four independent occasions [66], to generate stable diskinetoplastic forms, a loss that is compensated by distinct mutations on the ATP synthase $\gamma$-subunit [85]. A third, alternative hypothesis proposes that T. b. evansi and $T$. $b$. equiperdum underwent separate evolutionary processes from a $T$. b. brucei ancestor [17]. Our results are quite consistent with the existence of partially distinct evolutionary lineages, with the two new Venezuelan $T$. equiperdum strains, TeAp-N/D1 and TeGu-N/D1 corresponding to the recently proposed $T$. equiperdum groups 1 and 3 , respectively [66].

\section{Conclusion}

The microsatellite data divided the nine Venezuelan trypanosoma isolates into two groups, one closely related to $T$. evansi and a second, closely related to $T$. 
equiperdum (STIB841/OVI). The classification of TeAp$\mathrm{N} / \mathrm{D} 1$ and TeGu-N/D1 as T. equiperdum is supported by the sequences of their four maxicircle genes that are nearly identical to the orthologous $T$. brucei and T. equiperdum genes. Coinertia analysis of microsatellites and Procyclin PE repeats also place these two Venezuelan isolates close to the STIB841/OVI T. equiperdum strain. Phylogenetic analysis of the sequences of the $\operatorname{cox} 1$ gene, an exceptional discriminative molecular marker, separated the two isolates: TeAp-N/D1 clustered with the $T$. equiperdum STIB818 strain; while TeGu-N/D1 was grouped with the $T$. equiperdum STIB841/OVI strain. This constitutes the first molecular report of T. equiperdum strains isolated in Latin America (Fig. 4).

\section{Additional files}

\section{Additional file 1: Table S2-S9. Microsatellites from Venezuelan}

Trypanosoma spp. isolates,T. evansi, T. equiperdumandT. brucei bruceistrains. The microsatellite loci MORF2-CA, M6C8-CA, MT3033-AC/TC, MEST19-AT/ GT, MD2.349-CA and PE repeats of the PARP genes of T. evansi strains from South America (Colombia and Brazil), Asia (China) and Africa (Chad, Ethiopia and Kenya), T. equiperdum strains from Africa (South Africa) and Asia (China) and T. b. brucei from (Kenya, Gambia, Ivory Coast, Burkina Faso, Nigeria, Democratic Republic of Congo, Uganda and Tanzania). Further information on the strains can be found in the following references: T. evansi strains: E9/CO in [86], 2187 and 2191 in [87]; A, dog, equi Asia (China) and Africa (South Africa and Morocco), as well as nine Venezuelan Trypanosoma spp. isolates are presented. nd: not determined. and coati (DNA provided by Alberto M.R. Dávila, unpublished results), SH, ZJ, NJ, GX, JX, TC, ET and in [87]; KETRI2480 in [88, 89]. T. equiperdum strains: OVI in [87, 90]; BoTat-1.1 in [90, 91]; BJ in [48, 87]. (XLSX $41 \mathrm{~kb})$

Additional file 2: Table S1. Primers and PCR conditions used in this study. Figure S1. Diagram of amplicons and primers used to amplify the four maxicircle genes used in this study. Table S2. BLASTn analyses of cytochrome $b$ gene sequences from the TeAp-N/D1 isolate [GenBank Accession N N KP729379]. 1056 bp. Table S3. BLASTn analyses of cytochrome b gene sequences from the TeGu-N/D1 isolate [GenBank Accession Nº KP729380].1056 bp. Table S4. BLASTn analyses of Cytochrome Oxidase Subunit 1 gene sequences from the TeAp-N/D1 isolate [GenBank Accession No KP729381]. 1647 bp. Table S5. BLASTn analyses of Cytochrome Oxidase Subunit 1 gene sequences from the TeGu-N/D1 isolate sequence [GenBank Accession N ${ }^{\circ}$ KP729386]. 1530 bp. Table S6. BLASTn analyses of ATP synthase subunit 6 gene sequences from the TeAp-N/D1 isolate sequence [GenBank Accession Nº KP729385]. 285 bp. Table S7. BLASTn analyses of ATP synthase subunit 6 gene sequences from the TeGu-N/D1 isolate sequence [GenBank Accession N ${ }^{\circ}$ KP729382]. 285 bp. Table S8. BLASTn analyses of NADH dehydrogenase subunit 8 gene sequences from the TeAp-N/D1 isolate sequence [GenBank Accession N KP729383]. 342 bp. Table S9. BLASTn analyses of NADH dehydrogenase subunit 8 gene sequences from the TeGu-N/D1 isolate sequence [GenBank: KP729384]. 348 bp. (DOCX 69 kb)

\section{Competing interests}

The authors declare that they have no competing interests.

\section{Authors' contributions}

ES propagated some of the Trypanosoma spp. field isolates, performed maxicircle gene amplifications, analysis and phylogenetic trees and contributed to the manuscript draft. TP initiated the molecular characterization of the Venezuelan Trypanosome spp. isolates, including the genetic studies, participated in its coordination and contributed to the manuscript draft. GPR propagated some of the Trypanosoma spp. field isolates, performed maxicircle sequence analysis and alignments. IC propagated some of the Trypanosoma spp. field isolates, performed maxicircle sequence analysis and alignments. NB participated in the design, coordination and analysis of the microsatellite and Procyclin PE-genotyping experiments and contributed some unpublished genotyping results. PMA conceived the molecular characterization of the Venezuelan Trypanosome spp. isolates, including the genetic studies and participated in its coordination. AM participated in the design and coordination of the KDNA analysis, conceived the multivariate analysis of the microsatellite data and contributed to the manuscript draft. TB conceived and coordinated the microsatellites study and participated in its design and coordination. DB contributed to the design and coordination of the KDNA analysis. LBN designed and performed the Coinertia analysis. MG conceived the microsatellites and maxicircle gene analysis, participated in its design and coordination and contributed to the manuscript draft. All authors read and approved the final manuscript.

\section{Acknowledgements}

FONACIT Nº 2004000400 RIDMOH, G-98003462, Misión Ciencia 2007001425, Ecos Nord PI-2008002104, TRYPADVAC2 N. 003716, GID21-USB, Instituto Venezolano de Investigaciones Científicas (IVIC) $N^{\circ} 305$. We thank Howard Takiff for critically reading and editing of the manuscript.

\section{Author details}

'Laboratorio de Fisiología de Parásitos. Centro de Biofísica y Bioquímica, Instituto Venezolano de Investigaciones Científicas, Caracas, Venezuela. ${ }^{2}$ Grupo de Bioquímica e Inmunología de Hemoparásitos. Departamento de Biología Celular, Universidad Simón Bolívar, Caracas 1080, Venezuela. ${ }^{3}$ Laboratoire de Microbiologie Fondamentale et Pathogénicité, Université Bordeaux. UMR-CNRS 5234, 146, Rue Léo Saignat, 33076 Bordeaux, Cedex, France. ${ }^{4}$ CIRAD, UMR InterTryp, F-34398 Montpellier, France. ${ }^{5}$ Laboratorio de Biometría y Estadística, Área de Agricultura y Soberanía Alimentaria, Instituto de Estudios Avanzados, Caracas 1015A, Venezuela.

Received: 6 July 2015 Accepted: 1 October 2015

Published online: 15 October 2015

\section{References}

1. Stevens JR, Brisse S. Systematics of Trypanosomes of medical and veterinary importance. In: Maudlin I, Holmes PH, Miles MA, editors. The Trypanosomiases. Oxfordshire: CABI Publishing; 2004. p. 1-23.

2. Luckins AG, Dwinger RH. Non-tsetse-transmitted Animal Trypanosomiasis. In: Maudlin I, Holmes PH, Miles MA, editors. The Trypanosomiases. Oxfordshire: CABI Publishing; 2004. p. 269-81.

3. Desquesnes M. Trypanosomes and Diagnosis. In: Livestock Trypanosomoses and their Vectors in Latin America. Paris, France: Office International des Epizooties; 2004. p. 15-21. 65-83.

4. Desquesnes M, Holzmuller P, Lai DH, Dargantes A, Lun ZR, Jittaplapong S. Trypanosoma evansi and Surra: A Review and Perspectives on Origin, History, Distribution, Taxonomy, Morphology, Hosts, and Pathogenic Effects. BioMed Res Int. 2013;1-20.

5. Hoare CA. The Trypanosomes of mammals. A zoological monograph. Oxford: Blackwell Scientific Publications; 1972.

6. Canelón JL, Meléndez RD. Posible Origen del Trypanosoma evansi en Venezuela. Vet Tropica. 2003;28(2):155-67.

7. Silva-Iturriza A, Nassar JM, Garcia-Rawlins AM, Rosales R, Mijares A. Trypanosoma evansi kDNA minicircle found in the Venezuelan nectarfeeding bat Leptonycteris curasoae (Glossophaginae), supports the hypothesis of multiple origins of that parasite in South America. Parasitol Int. 2013;62(2):95-9.

8. Levine ND. Tratado de Parasitología Veterinaria. Zaragoza: Editorial Acribia; 1983

9. Villareal MV, Mingala CN, Rivera WL. Molecular characterization of Trypanosoma evansi isolates from water buffaloes (Bubalus bubalis) in the Philippines. Acta Parasitol. 2013;58(1):6-12.

10. Desquesnes M, Dargantes A, Lai DH, Lun ZR, Holzmuller P, Jittapalapong S. Trypanosoma evansi and Surra: A Review and Perspectives on Transmission, Epidemiology and Control, Impact, and Zoonotic Aspects. BioMed Res Int. 2013;2013:321237.

11. Desquesnes M, Bossard G, Thevenon S, Patrel D, Ravel S, Pavlovic D, et al. Development and application of an antibody-ELISA to follow up a Trypanosoma evansi outbreak in a dromedary camel herd in France. Vet Parasitol. 2009;162(3-4):214-20.

12. Gutierrez C, Desquesnes M, Touratier L, Buscher P. Trypanosoma evansi: recent outbreaks in Europe. Vet Parasitol. 2010;174(1-2):26-9. 
13. Defontis M, Richartz J, Engelmann N, Bauer C, Schwierk VM, Buscher P, et al. Canine Trypanosoma evansi infection introduced into Germany. Vet Clin Pathol. 2012;41(3):369-74.

14. Brun $\mathrm{R}$, Hecker H, Lun ZR. Trypanosoma evansi and T. equiperdum: distribution, biology, treatment and phylogenetic relationship (a review). Vet. Parasitol. 1998:79(2):95-107.

15. Gibson W, Miles M. Frontiers in research on parasitic protozoa. Trends Parasitol. 2002;18(12):521-2

16. Claes F, Buscher P, Touratier L, Goddeeris BM. Trypanosoma equiperdum: master of disguise or historical mistake? Trends Parasitol. 2005;21(7):316-21.

17. Wei Y, Wen Y-Z., Desquesnes, M., Lun, Z-R. Molecular Epidemiology of Trypanosoma evansi and T. equiperdum and Atypical Human Infection by Animal Trypanosomes. In: The Molecular Epidemiology of Trypanosomes and Leishmania. NY, NY 10013, USA: Geoff Hide; 2011: p. 1-14

18. Scacchia M, Camma C, Di Francesco G, Di Provvido A, Giunta R, Luciani M, et al. A clinical case of dourine in an outbreak in Italy. Vet Ital. 2011:47(4):473-5. 469-472.

19. Calistri $P$, Narcisi $V$, Atzeni M, De Massis F, Tittarelli M, Mercante MT, et al. Dourine Reemergence in Italy. J Equine Vet Sci. 2013;33(2):83-9.

20. Pascucci I, Di Provvido A, Camma C, Di Francesco G, Calistri P, Tittarelli M, et al. Diagnosis of dourine in outbreaks in Italy. Vet Parasitol. 2013;193(1-3):30-8.

21. Vulpiani MP, Carvelli A, Giansante D, lannino F, Paganico D, Ferri N Reemergence of Dourine in Italy: Clinical Cases in Some Positive Horses. J Equine Vet Sci. 2013;33(6):468-74

22. CFSPH and IICAB. http://www.cfsph.iastate.edu/Factsheets/pdfs/dourine.pdf (2009). Accessed 01 April 2015.

23. Hide G, Cattand P, LeRay D, Barry JD, Tait A. The identification of Trypanosoma brucei subspecies using repetitive DNA sequences. Mol Biochem Parasitol. 1990;39(2):213-25.

24. Haag J, O'hUigin C, Overath P. The molecular phylogeny of trypanosomes: evidence for an early divergence of the Salivaria. Mol Biochem Parasitol. 1998;91(1):37-49.

25. Stevens JR, Gibson W. The molecular evolution of trypanosomes. Parasitol Today. 1999;15(11):432-7.

26. Stevens JR, Noyes HA, Schofield CJ, Gibson W. The molecular evolution of Trypanosomatidae. Adv Parasitol. 2001;48:1-56.

27. Hamilton PB, Adams ER, Malele, II, Gibson WC. A novel, highthroughput technique for species identification reveals a new species of tsetse-transmitted trypanosome related to the Trypanosoma brucei subgenus, Trypanozoon. Infect. Genet. Evol. 2008; doi:10.1016/ j.meegid.2007.09.003

28. Boid R. Isoenzyme characterisation of 15 stocks of Trypanosoma evans isolated from camels in the Sudan. Trop Med Parasitol. 1988;39(1):45-50.

29. Stevens JR, Nunes VL, Lanham SM, Oshiro ET. Isoenzyme characterization of Trypanosoma evansi isolated from capybaras and dogs in Brazil. Acta Trop. 1989:46(4):213-22

30. Queiroz AO, Cabello PH, Jansen AM. Biological and biochemical characterization of isolates of Trypanosoma evansi from Pantanal of Matogrosso-Brazil. Vet Parasitol. 2000;92(2):107-18.

31. Paindavoine $P$, Pays E, Laurent M, Geltmeyer $Y$, Le Ray D, Mehlitz D, et al The use of DNA hybridization and numerical taxonomy in determining relationships between Trypanosoma brucei stocks and subspecies. Parasitology. 1986:92(Pt 1):31-50.

32. Mathieu-Daude F, Bicart-See A, Bosseno MF, Breniere SF, Tibayrenc M. Identification of Trypanosoma brucei gambiense group I by a specific kinetoplast DNA probe. Am J Trop Med Hyg. 1994;50(1):13-9.

33. Li FJ, Gasser RB, Lai DH, Claes F, Zhu XQ, Lun ZR. PCR approach for the detection of Trypanosoma brucei and $T$. equiperdum and their differentiation from T. evansi based on maxicircle kinetoplast DNA. Mol. Cell Probes. 2007; doi:10.1016/..mcp.2006.03.009

34. Biteau N, Bringaud F, Gibson W, Truc P, Baltz T. Characterization of Trypanozoon isolates using a repeated coding sequence and microsatellite markers. Mol Biochem Parasitol. 2000;105(2):187-202.

35. Weber JL. Informativeness of human (dC-dA)n. (dG-dT)n polymorphisms. Genomics. 1990;7(4):524-30.

36. Valadares HM, Pimenta JR, de Freitas JM, Duffy T, Bartholomeu DC, Oliveira Rde P et al. Genetic profiling of Trypanosoma cruzi directly in infected tissues using nested PCR of polymorphic microsatellites. Int. J. Parasitol. 2008; doi:10.1016/ j.jpara.2007.10.017

37. Weber JL, Wong C. Mutation of Human Short Tandem Repeats. Hum. Mol. Genet. 1993; doi: 10.1093/Hmg/2.8.1123
38. Hughes CR, Queller DC. Detection of highly polymorphic microsatellite loci in a species with little allozyme polymorphism. Mol Ecol. 1993;2(3):131-7.

39. Jenni L, Marti S, Schweizer J, Betschart B, Lepage RWF, Wells JM et al. Hybrid Formation between African Trypanosomes during Cyclical Transmission. Nature. 1986; doi: 10.1038/322173a0

40. Capewell P, Cooper A, Duffy CW, Tait A, Turner CM, Gibson W et al. Human and animal Trypanosomes in Cote d'Ivoire form a single breeding population. PLoS One. 2013; doi:10.1371/journal.pone.0067852

41. Simo G, Sobgwi PF, Njitchouang GR, Njiokou F, Kuiate JR, Cuny G et al. Identification and genetic characterization of Trypanosoma congolense in domestic animals of Fontem in the South-West region of Cameroon. Infect. Genet. Evol. 2013; doi:10.1016/j.meegid.2013.04.019

42. Yurchenko V, Kolesnikov AA. Minicircular kinetoplast DNA from Trypanosomatidae. Mol Biol. 2001;35:3-13.

43. Pollard WW, Rohrer SP, Michelotti EF, Hancock K, Hajduk SL. Organization of minicircle genes for guide RNAs in Trypanosoma brucei. Cell. 1990;63(4):783-90.

44. Borst P, Fase-Fowler F, Gibson WC. Kinetoplast DNA of Trypanosoma evansi. Mol Biochem Parasitol. 1987;23(1):31-8.

45. Ou YC, Giroud C, Baltz T. Kinetoplast DNA analysis of four Trypanosoma evansi strains. Mol Biochem Parasitol. 1991;46(1):97-102.

46. Songa EB, Paindavoine P, Wittouck E, Viseshakul N, Muldermans S, Steinert $M$, et al. Evidence for kinetoplast and nuclear DNA homogeneity in Trypanosoma evansi isolates. Mol Biochem Parasitol. 1990;43(2):167-79.

47. Lun ZR, Brun R, Gibson W. Kinetoplast DNA and molecular karyotypes of Trypanosoma evansi and Trypanosoma equiperdum from China. Mol Biochem Parasitol. 1992;50(2):189-96.

48. Myler PJ. Molecular variation in trypanosomes. Acta Trop. 1993;53(3-4):205-25

49. Borst P, Fase-Fowler F. The maxi-circle of Trypanosoma brucei kinetoplast DNA. Biochim Biophys Acta. 1979;565(1):1-12.

50. Clayton CE, Michels P. Metabolic compartmentation in African trypanosomes. Parasitol Today. 1996;12(12):465-71.

51. Lai DH, Hashimi H, Lun ZR, Ayala FJ, Lukes J. Adaptations of Trypanosoma brucei to gradual loss of kinetoplast DNA: Trypanosoma equiperdum and Trypanosoma evansi are petite mutants of T. brucei. Proc. Natl. Acad. Sci. U. S. A. 2008; doi:10.1073/pnas.0711799105

52. Perrone TM, Gonzatti MI, Villamizar G, Escalante A, Aso PM. Molecular profiles of Venezuelan isolates of Trypanosoma sp. by random amplified polymorphic DNA method. Vet. Parasitol. 2009; doi:10.1016/ j.vetpar.2009.01.034

53. Holzmuller P, Grebaut $P$, Peltier JB, Brizard JP, Perrone T, Gonzatti M et al, Secretome of animal trypanosomes. Ann. N. Y. Acad. Sci. 2008; doi:10.1196/ annals. 1428.097

54. Lanham SM, Godfrey DG. Isolation of salivarian trypanosomes from man and other mammals using DEAE-cellulose. Exp Parasitol. 1970;28(3):521-34.

55. COBIANIM: The COBIANIM register. http://www.ivic.gob.ve/cobianim/. Accessed 30 May 2015

56. Kiers HAL. Simple Structure in Component Analysis Techniques for Mixtures of Qualitative and Quantitative Variables. Psychometrika. 1991;56(2):197-212. doi:10.1007/Bf02294458.

57. Hill MO, Smith AJE. Principal Component Analysis of Taxonomic Data with Multistate Discrete Characters. Taxon. 1976; doi:10.2307/1219449

58. Doledec S, Chessel D. Coinertia Analysis - an Alternative Method for Studying Species Environment Relationships. Freshwater Biol. 1994; doi:10.1111/j.1365-2427.1994.tb01741.x

59. Dray S, Chessel D, Thioulouse J. Coinertia analysis and the linking of ecological data tables. Ecology. 2003; doi:10.1890/03-0178

60. Chessel D, Dufour AB, Thioulouse J. The ade4 package-l- One-table methods. R News. 2004;4:5-10.

61. Dray S, Dufour AB. The ade4 package: Implementing the duality diagram for ecologists. J Stat Softw. 2007;22(4):1-20.

62. Dray S, Dufour AB, Chessel D. The ade4 package-II: Two-table and K-table methods. R News. 2007;7(2):47-52.

63. Tamura K, Peterson D, Peterson N, Stecher G, Nei M, Kumar S. MEGA5: molecular evolutionary genetics analysis using maximum likelihood, evolutionary distance, and maximum parsimony methods. Mol. Biol. Evol. 2011; doi:10.1093/molbev/msr121

64. Gibson W. Resolution of the species problem in African trypanosomes. Int. J. Parasitol. 2007; doi:10.1016/j.jpara.2007.03.002 
65. Hamilton PB, Gibson WC, Stevens JR. Patterns of co-evolution between trypanosomes and their hosts deduced from ribosomal RNA and proteincoding gene phylogenies. Mol. Phylogenet. Evol. 2007; doi:10.1016/ j.ympev.2007.03.023

66. Carnes J, Anupama A, Balmer O, Jackson A, Lewis M, Brown R et al. Genome and phylogenetic analyses of trypanosoma evansi reveal extensive similarity to T. brucei and multiple independent origins for dyskinetoplasty. PLoS Negl. Trop. Dis. 2015; doi:10.1371/journal.pntd.0003404

67. Lun ZR, Lai DH, Li FJ, Lukes J, Ayala FJ. Trypanosoma brucei: two steps to spread out from Africa. Trends. Parasitol. 2010; doi:10.1016/j.pt.2010.05.007

68. Bhat GJ, Koslowsky DJ, Feagin JE, Smiley BL, Stuart K. An extensively edited mitochondrial transcript in kinetoplastids encodes a protein homologous to ATPase subunit 6. Cell. 1990;61(5):885-94.

69. Souza AE, Myler PJ, Stuart K. Maxicircle CR1 transcripts of Trypanosoma brucei are edited and developmentally regulated and encode a putative iron-sulfur protein homologous to an NADH dehydrogenase subunit. Mol Cell Biol. 1992:12(5):2100-7.

70. Feagin JE, Jasmer DP, Stuart K. Developmentally regulated addition of nucleotides within apocytochrome b transcripts in Trypanosoma brucei. Cell. 1987;49(3):337-45

71. Schnaufer A, Domingo GJ, Stuart K. Natural and induced dyskinetoplastic trypanosomatids: how to live without mitochondrial DNA. Int J Parasitol. 2002;32(9):1071-84.

72. Jensen RE, Simpson L, Englund PT. What happens when Trypanosoma brucei leaves Africa. Trends. Parasitol. 2008; 24(10): doi:10.1016/ j.pt.2008.06.007.

73. Dean S, Gould MK, Dewar CE, Schnaufer AC. Single point mutations in ATP synthase compensate for mitochondrial genome loss in trypanosomes. Proc. Natl. Acad. Sci. U. S. A. 2013; doi:10.1073/pnas.1305404110.80

74. Blair D, Agatsuma T, Watanobe T, Okamoto M, Ito A. Geographical genetic structure within the human lung fluke, Paragonimus westermani, detected from DNA sequences. Parasitology. 1997;115(Pt 4):411-7.

75. Morgan JA, Blair D. Relative merits of nuclear ribosomal internal transcribed spacers and mitochondrial CO1 and ND1 genes for distinguishing among Echinostoma species (Trematoda). Parasitology. 1998;116(Pt 3):289-97.

76. Mas-Coma S, Bargues MD. Populations, hybrids and the systematic concepts of species and subspecies in Chagas disease triatomine vectors inferred from nuclear ribosomal and mitochondrial DNA. Acta Trop. 2009;110(2-3):112-36.

77. OIE: The OIE register. http://web.oie.int/hs2/ sit_mald_cont.asp?c_mald=60\&c_cont=2. Accessed 10 April 2015

78. Rivas-Larralde G. Un caso de durina en Venezuela. Revista de Medicina Veterinaria y Parasitología. 1939;1:192

79. Caporale VP, Battelli G, Semproni G. Epidemiology of dourine in the equine population of the Abruzzi Region. Zentralbl Veterinarmed B. 1980;27(6):489-98.

80. Zablotskij VT, Georgiu C, de Waal T, Clausen PH, Claes F, Touratier L. The current challenges of dourine: difficulties in differentiating Trypanosoma equiperdum within the subgenus Trypanozoon. Rev Sci Tech. 2003;22(3):1087-96.

81. Gari FR, Ashenafi H, Tola A, Goddeeris BM, Claes F. Comparative diagnosis of parasitological, serological, and molecular tests in dourine-suspected horses. Trop. Anim. Health Prod. 2010; doi:10.1007/s11250-010-9615-1

82. Hagos A, Degefa G, Yacob H, Fikru R, Alemu T, Feseha G, et al. Seroepidemiological survey of trypanozoon infection in horses in the suspected dourine-infected Bale highlands of the Oromia region, Ethiopia. Rev Sci Tech. 2010;29(3):649-54

83. OIE: The OIE register. http://www.oie.int/fileadmin/Home/fr/ Health_standards/tahm/2.05.03_DOURINE.pdf. Accessed 01 April 2015.

84. Lun ZR, Desser SS. Is the broad range of hosts and geographical distribution of Trypanosoma evansi attributable to the loss of maxicircle kinetoplast DNA? Parasitol. Today. 1995; doi:10.1016/0169-4758(95)80129-4

85. Schnaufer A. Evolution of dyskinetoplastic trypanosomes: how, and how often? Trends Parasitol. 2010; doi:10.1016/j.pt.2010.08.001

86. Gibson WC, de C Marshall TF, Godfrey DG. Numerical analysis of enzyme polymorphism: a new approach to the epidemiology and taxonomy of trypanosomes of the subgenus Trypanozoon. Adv Parasitol. 1980;18:175-246.

87. Zhang ZQ, Baltz T. Identification of Trypanosoma evansi, Trypanosoma equiperdum and Trypanosoma brucei brucei using repetitive DNA probes. Vet Parasitol. 1994;53(3-4):197-208.

88. Gibson WC, Wilson AJ, Moloo SK. Characterisation of Trypanosoma (Trypanozoon) evansi from camels in Kenya using isoenzyme electrophoresis. Res Vet Sci. 1983;34(1):114-8.
89. Stevens JR, Lanham SM, Allingham R, Gashumba JK. A simplified method for identifying subspecies and strain groups in Trypanozoon by isoenzymes. Ann Trop Med Parasitol. 1992;86(1):9-28.

90. Gillingwater K, Buscher P, Brun R. Establishment of a panel of reference Trypanosoma evansi and Trypanosoma equiperdum strains for drug screening. Vet. Parasitol. 2007; doi:10.1016/j.vetpar.2007.05.020

91. Baltz T, Baltz D, Giroud C, Crockett J. Cultivation in a semi-defined medium of animal infective forms of Trypanosoma brucei, T. equiperdum, T. evansi, T. rhodesiense and T. gambiense. EMBO J. 1985;4(5):1273-7.

\section{Submit your next manuscript to BioMed Central and take full advantage of:}

- Convenient online submission

- Thorough peer review

- No space constraints or color figure charges

- Immediate publication on acceptance

- Inclusion in PubMed, CAS, Scopus and Google Scholar

- Research which is freely available for redistribution

Submit your manuscript at www.biomedcentral.com/submit 